\title{
Improvements in CanMEDS competencies for medical students in an interdisciplinary and voluntary setting
}

This article was published in the following Dove Press journal:

Advances in Medical Education and Practice

12 December 2014

Number of times this article has been viewed

\author{
Mads Dam Vildbrad \\ Johanne Marie Lyhne \\ International Medical Cooperation \\ Committee, Aarhus University, \\ Aarhus, Denmark
}

Correspondence: Mads Dam Vildbrad International Medical Cooperation Committee, Medicinerhuset, Building | |6I, Ole Worms Allé 3, DK-8000 Aarhus, Denmark Tel +45 20450486 Email mads.dam.vildbrad@gmail.com
Background: To practice medicine, doctors must master leadership, communication, team management, and collaboration, in addition to medical knowledge. The CanMEDS framework describes seven roles of a doctor, but the six nonmedical expert roles are de-emphasized in the academic medical curriculum. Innovative opportunities are needed for medical students to develop as participants in a world of interdisciplinary health care.

Methods: We founded a volunteer-based, interdisciplinary, student-run project called SUNDdag (HEALTHday) with 60 students from 12 different educational backgrounds. To evaluate the learning outcomes of the project, we conducted a cross-sectional study using an anonymous, self-administered questionnaire.

Results: Students joined the project due to it being health-promoting, volunteer-based, and interdisciplinary. The medical students reported a significant increase of skills in all seven roles except for "medical expert". They reported an increased understanding of the non-health-related students' skills.

Conclusion: In their future careers, medical students must collaborate with health care professionals in a team-based approach to patient care and with non-health-related professionals in administrative tasks. Interdisciplinary volunteer-based initiatives like SUNDdag are potential platforms for medical students to improve their CanMEDS competencies. We encourage students to initiate similar projects and we encourage faculties to support volunteer-based, interdisciplinary initiatives due to their favorable cost-benefit ratio.

Keywords: medical education, voluntarism, interprofessional education, medical students

\section{Introduction}

Medical students experience a significant change in expectations going from undergraduate to post-graduate training. In addition to being competent clinicians, postgraduate medical doctors are also expected to be leaders, and master communication and collaboration as well as team management skills. ${ }^{1-4}$ These skills are increasingly important in health care systems that are more and more team-based. ${ }^{5-8}$

CanMEDS named seven now well-known roles or qualities for a medical doctor to possess in order to fulfill all their professional responsibilities. ${ }^{9}$ These qualities have since been sought implemented as the backbone of medical under- and postgraduate education, throughout the world - including Denmark. ${ }^{10-13}$ The six nonmedical expert competencies are very important but are often de-emphasized in the medical curriculum. . $12,14,15$ The curriculum traditionally focuses on scientific medical knowledge (ie, "medical expert"), which constantly expands as a result of massive research and hence compresses the space in the curriculum for training in the other competencies. 
There is increasing consensus that education of more than the "medical expert" role is necessary. $4,16-19$

The required skills of communication and collaboration can be taught through interprofessional education, which offers valuable experience for medical students., ${ }^{4,20-22}$ Interprofessional education may enhance patient safety and outcomes, as well as promote networking, reflection, and insight into the skills of other professionals. ${ }^{4,5,15,20,23,24}$ Unfortunately, most interdisciplinary interventions have been performed in clinical settings, ${ }^{7,22,25,26}$ which focus on the "medical expert" role.

To date, teaching the six nonmedical expert roles has been limited. 1,2,12,15,16,22,27 New innovative opportunities are needed for medical students to improve in all seven roles. We founded a volunteer-based, interdisciplinary, student-run initiative called SUNDdag (HEALTHday). We hypothesized that such a project might provide an opportunity for medical students to develop their competencies; however, the magnitude of medical students' improvement in the seven CanMEDS roles in volunteerbased and interdisciplinary settings remains unknown. The aim of this study was to evaluate the perceived increase in skills of medical students participating in SUNDdag.

\section{Materials and methods}

\section{Aim of the project}

SUNDdag (HEALTHday) was an annual, large event concerning public health and prevention in the local community due to the effectiveness of prevention. ${ }^{28,29}$ SUNDdag aimed to be socially accountable in our interaction with the public to impact people's health positively and meet priority health needs in society. ${ }^{30}$ We aimed to help people initiate lifestyle changes. SUNDdag was placed in a well-trafficked downtown area, aiming to interact with passersby and present them with inspirational initiatives for a healthier lifestyle. We focused on motivation, diet, exercise, and body function. On the passerby, we measured physiological parameters that people meet extensively in the media but often lack understanding of or interest in. We hoped to make concepts such as "blood pressure", "lung function", "blood sugar", and "body fat percentage" more personal and relevant for each person, so they would take a greater interest in their own health. All measurements were followed up by qualified comments and recommendations. Well-known experts gave presentations regarding their own field of interest, and were used in our advertisements.

\section{The project}

We founded the SUNDdag project in Aarhus, Denmark, in 2011 as part of the International Medical Cooperation
Committee, which is the Danish member organization of the International Federation of Medical Students' Associations. SUNDdag was first held in 2012 and repeated and extended in 2013. In these 2 years, approximately 30,000 people visited SUNDdag and more than $€ 60,000$ in funding was raised. Sponsors included private and public funding sources, including the Ministry of Health and Prevention, the Central Denmark Region, Aarhus University, and the municipality of Aarhus. The event was free of charge to avoid unequal access based on socioeconomic status, which is fundamental in health care. Our collaborators included many public and private institutions as well as companies working with health and prevention, so the volunteers could learn in the context that would apply when they graduated. ${ }^{17}$

The event was organized via monthly meetings of volunteers who were divided into working groups that often held additional meetings. The meetings usually lasted 2-3 hours. We calculated that SUNDdag 2013 required 3,500 volunteer working hours.

\section{Organizing group}

When founding SUNDdag, we ensured multiple health and organizational aspects in its content to attract many types of volunteers with different interests. We advertised throughout the university campus, and 60 students from 12 different disciplines volunteered during the 2 years (Table 1 ). The diversity of the organizing group was a strength of the project, creating a broad foundation of knowledge to be drawn upon. Different students with different points of view, from different

Table I Sixty volunteers who engaged in SUNDdag categorized according to sex and educational background

\section{(n)}

Sex

Male

14

Female

Health-related education

Medicine

18

Public health

23

Physiotherapy

Nursing

Nutrition and health

Sports

Non-health-related education

Communication

Economy

Journalism

Esthetics and culture

Architecture

Digital design

Total 
backgrounds improved group dynamics and efficiency. ${ }^{6}$ Students from communications and journalism worked on public relations, students from architecture and esthetics contributed their graphic design talents, students from economics and business schools guided fundraising strategies and logistics, and students from health science disciplines created the health-related content of SUNDdag.

The volunteers were urged only to sign up for tasks that they could actually fulfill, given their reality of being both a volunteer and a full-time student. Additionally, we encouraged group members to participate not only in working groups in their own field, but also in interdisciplinary working groups and tasks across fields of study, in order to learn from each other and gain competencies relevant for their future careers.

\section{Evaluation by questionnaire}

We evaluated learning outcomes with a cross-sectional study using a self-administered, anonymous questionnaire. No ethical approval was required because the purpose of the questionnaire, its anonymity, and the voluntary nature of responding were disclosed to the respondents in writing. The questionnaire was sent out one year after the second event, to ensure the respondents had time to reflect upon the outcomes. The questionnaire was constructed using SurveyXact and distributed by email to all 60 participants who had taken part in the organization of either the first, second, or both years.

The questionnaire was specially constructed to evaluate the aim of the present study. It contained questions regarding demographic background, reasons for participation, and perceived outcomes. The medical students received an additional nine questions: two regarding their understanding of the competencies of other professions after participation in SUNDdag and one question about each of the seven roles of a doctor, ${ }^{9}$ and whether participation in SUNDdag had influenced their skills in each of these roles. The Danish interpretation of each role ${ }^{10}$ was included in the questions to obtain an objective and thorough description of each role. Due to the complex nature of the project, we found it reasonable to ask for learning outcomes in all seven competencies. Questions were evaluated on a 7-point Likert scale, with the number 4 being the neutral option and with an equal number of positive and negative options.

\section{Statistical analysis}

All data are shown as the mean \pm standard error of the mean, unless stated otherwise. When appropriate, a one-sample $t$-test was performed to test if the results differed significantly from the neutral value of 4 , and hence constituted a significant positive or negative answer. Due to the sample size regarding the additional questions for medical students ( $\mathrm{n}=17$, one did not complete the questionnaire), these data was analyzed with a nonparametric test. The data analysis was performed in SurveyXact and GraphPad Prism (version 6.0, GraphPad Software Inc., San Diego, CA, USA). A $P$-value less than 0.05 was considered to be statistically significant.

\section{Results}

Fifty-four volunteers answered the questionnaire (92\%), of whom $13(24 \%)$ were males and $18(33 \%)$ were medical students. The mean age of the volunteers when they engaged in SUNDdag was 23.2 years, and participants had studied for an average of 4.1 semesters ( 2 years) when they joined SUNDdag.

The respondents reported that they had joined SUNDdag because the project was health-promoting (81\%), volunteer-based (70\%), interdisciplinary (61\%), and local (24\%), and the responses from medical students were $94 \%, 83 \%, 56 \%$, and $50 \%$, respectively. The medical students perceived that participation in SUNDdag improved their skills in six of the seven CanMEDS competencies for a doctor (Figure 1).

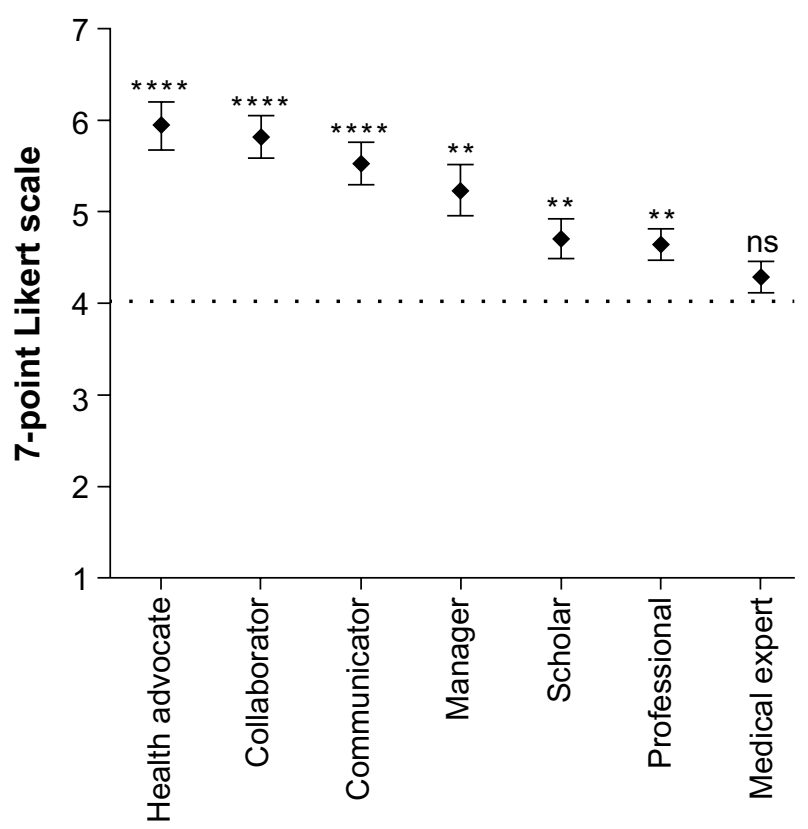

Figure I Results from the medical students $(n=17)$ regarding the seven roles of a doctor. All questions included the Danish description of each role followed by "On a scale from I to 7, with I being 'very much disagree', 4 being 'neutral' and 7 being 'very much agree', how did your participation in SUNDdag affect your competencies as 'role'?" Horizontal dotted line indicates a neutral value. Data are shown as the mean \pm standard error of the mean, nonparametric test. $* * P<0.0$ I, $* * * * P<0.000$ I versus the neutral value of 4 .

Abbreviation: ns, non-significant. 
The medical students did not increase their understanding of the skills of students in other health professions $(4.6 \pm 0.4$, $95 \%$ confidence interval [CI] 3.8-5.4, not statistically significant); however, they reported a significant increase in their understanding of non-health-related student competencies $(5.1 \pm 0.3,95 \%$ CI 4.3-5.8, $P<0.05)$.

The outcomes for all students are presented in Table 2. Question C regarding interdisciplinary training at university divided the responses on the 7-point Likert scale. Public health students reported a satisfactory amount of interdisciplinary exposure $(5.1 \pm 0.4,95 \%$ CI $4.3-5.8, P<0.05)$, whereas medical students' responses trended toward a lack of interdisciplinary training (3.2 \pm 0.4 , 95\% CI 2.4-4.0, $P=0.075)$. In contrast, medical students highly valued the usefulness of interdisciplinary training in question D $(6.0 \pm 0.2$, 95\% CI 5.5-6.5, $P<0.0001)$.

\section{Discussion}

\section{The seven roles}

The vast majority of volunteers were assigned multiple tasks, training in a diversity of skill sets, and collaboration across specializations; therefore, we felt it was reasonable to assess student-perceived advances in all seven CanMEDS competencies. Our results revealed that medical students reported perceived improvement in six CanMEDS roles through participation in SUNDdag (Figure 1). It seems that this type of activity provides opportunity for such learning to occur.

Table 2 Results of the nine questions for all respondents $(n=54)$

\begin{tabular}{|c|c|}
\hline & Mean \pm SEM \\
\hline \multicolumn{2}{|l|}{$\begin{array}{l}\text { On a scale from I to } 7 \text {, with I being "very much } \\
\text { disagree", } 4 \text { being "neutral", and } 7 \text { being }\end{array}$} \\
\hline \multicolumn{2}{|l|}{ "very much agree", how much do you agree: } \\
\hline a. Voluntary work is beneficial for my education/career & $6.0 \pm 1.4^{* * * *}$ \\
\hline $\begin{array}{l}\text { b. It benefits my job chances to improve my skills } \\
\text { through voluntary work (eg, by courses, learning } \\
\text { by doing) }\end{array}$ & $6.0 \pm 1.3 * * * *$ \\
\hline $\begin{array}{l}\text { c. My education offers sufficient amount of } \\
\text { interdisciplinary learning }\end{array}$ & $4.0 \pm 0.2$ \\
\hline $\begin{array}{l}\text { d. Undergraduate interdisciplinary training is useful } \\
\text { for my future job }\end{array}$ & $6.2 \pm 0.1 * * * *$ \\
\hline $\begin{array}{l}\text { e. Participation in SUNDdag has made me ready } \\
\text { for post-graduate interdisciplinary teamwork }\end{array}$ & $4.9 \pm 0.2^{* * * *}$ \\
\hline $\begin{array}{l}\text { f. I have achieved skills through SUNDdag that } \\
\text { I could not have achieved in my education }\end{array}$ & $5.1 \pm 0.2^{* * * *}$ \\
\hline $\begin{array}{l}\text { g. The voluntary work in SUNDdag was worth } \\
\text { the time spent }\end{array}$ & $6.0 \pm 0.1 * * * *$ \\
\hline $\begin{array}{l}\text { h. The voluntary work in SUNDdag was a strain } \\
\text { on me/my education }\end{array}$ & $2.4 \pm 0.2^{* * * *}$ \\
\hline i. I will put SUNDdag on my resume & $6.2 \pm 0.2 * * * *$ \\
\hline
\end{tabular}

Note: $* * * * P<0.0001$ versus the neutral value of 4 . Abbreviation: SEM, standard error of the mean.
The role of "health advocate" had the highest improvement score in our project. This is obvious because the event concerned public health in our city, and our volunteers worked with health prevention innovatively to rethink it into a public event by transforming their theoretical knowledge into digestible health prevention initiatives. Local health advocacy has previously been successfully implemented in medical curricula, ${ }^{31}$ but our results indicate that it is also achievable through extracurricular voluntarism. However, Stafford et al ${ }^{12}$ reported a discrepancy between residents' endorsement of this role and their participation in health advocacy. Hopefully, undergraduate involvement in health advocacy with interdisciplinary aspects will continue in the post-graduate years among our medical students, because the role is important for future physicians to be socially responsible. ${ }^{17}$

"Collaborator" had the second highest score of improvement in our study. Collaboration increases in importance as treatment of patients becomes team-based, ${ }^{5,8}$ and it is recommended as an area of focus for medical students by the World Health Organization. ${ }^{32}$ However, as shown in Figure 2, collaboration does not only concern cooperation in medical settings. The collaboration of a medical doctor can be divided into two, ie, the ability to collaborate in health-related and in non-health-related settings. Likewise, the medical students in SUNDdag practiced collaboration with both health-related and non-health-related colleagues (Figure 2).

The medical student organizers of SUNDdag gained experience cooperating with many health-related associations and institutions, mimicking the necessary health-related collaboration of a medical doctor (Figure 2, left side). This undergraduate experience can be difficult to achieve, because all health-related disciplines are divided according to professions (eg, medicine, nursing, physiotherapy). Health care students

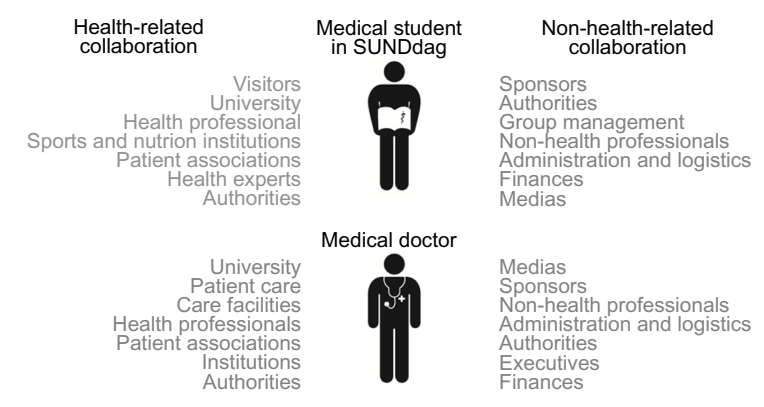

Figure 2 Collaboration for medical students in SUNDdag and for medical doctors in general. Both must master collaboration with health-related professions and institutions (left side) and with non-health-related professions and institutions (right side) through their work. The collaborators are listed in random order. The figure shows that many collaborators are similar, illustrating the educational value for medical students in a voluntary, interdisciplinary project like SUNDdag. The experiences will be useful to handle health-related as well as non-health-related tasks after graduation. 
from different disciplines do not learn to cooperate prior to graduation, increasing the risk of problematic stereotyping. ${ }^{7,15}$ Medical students may develop a misunderstanding of the competencies of other health professions and show a shortage of collaboration, ${ }^{4}$ which can reduce the outcome of future teamwork in a health care environment. ${ }^{33}$ Interdisciplinary clinical training has been shown to improve cooperation with other clinical students, where all employ their clinical skills. , $^{4,20-22}$ However, this was not the case in our project, because the medical students did not report a significant increase in their understanding of the skills of other clinical students. This was likely due to the fact that clinical aspects of patient care were not the focus of SUNDdag.

Alternatively, our medical students learned to collaborate with authorities and institutions of the nonmedical world and cooperate with non-health-related professions, which explains why they reported a significant increase in understanding of their skills (Figure 2, right side). Medical doctors likewise need to cooperate with domains outside medicine, ${ }^{5,16}$ and initiatives like SUNDdag that engage students from different faculties offer educational experience. This knowledge and acceptance of others' competencies is of key importance in future cooperation, administration, and negotiation, where nonclinical factors affect decision-making. ${ }^{16,27}$

Our responders reported increased skills in the role of "communicator". Communication is often missing in medical school curricula despite medical students acknowledging its importance. ${ }^{13,34}$ In concordance with our findings, communication has previously been taught through interprofessional education of medical students. ${ }^{15}$ It seems important to train in communication before graduation to achieve effects, given that Rice et $\mathrm{al}^{34}$ could not change communication in an interventional study with educated health workers. The obstacles reported were professional resistance and the medical hierarchy, which could be the result of undergraduate stereotyping from discipline divided educations. Therefore interdisciplinary training is encouraged. ${ }^{7}$ The work in SUNDdag required communication internally with both health and non-health-related students, with organizations, authorities, companies, sponsors, and media organizations prior to the event, and with the public on the day of the event. The variety of communicational experiences was particularly beneficial for medical students, as medical doctors must master communication at different levels and with different topics. ${ }^{10}$ Communication is also vital in many of the other discussed roles of the doctor.

The role of "manager" is of growing importance for doctors, but despite the fact that medical students perceive the need for leadership, a shortage of training in this role has been reported. ${ }^{1,12,14}$ This role is important in many situations, eg, clinical team work, hospital executive performance, and private practice. ${ }^{2,35}$ As leader, the doctor fulfills the link between clinical practice and organizational performance, hospital management, and economics..$^{3,19,23,27}$ In SUNDdag, medical students learned leadership through decisionmaking, economic responsibility, organizational logistics, and group management.

The "scholar role" was practiced in SUNDdag through reading of evidence-based arguments to persuade sponsors and collaborators. Many dealt with areas of knowledge beyond the regular medical curriculum. If medical students feel a shortage of training in any of the competencies, they can through volunteerism take responsibility for their own learning, which is also part of the "scholar" role. ${ }^{10}$

"Professional" is a broad role that emcompasses ethics, care, social responsibility, conscientiousness, respect for patient autonomy, clinical teamwork, and a relevant balance between career and private life..$^{8,10,17,18}$ It is rated by medical students as one of the most important roles. ${ }^{13}$ Our medical students reported a positive effect from participation where voluntary work and studying had to be handled at the same time. Ethics is important in public health, and has previously been taught in interprofessional settings $;{ }^{24}$ our results suggest that this is also possible in volunteer settings.

The "medical expert" role is the main focus in medical school, and no improvement was seen in our study. We did not expect medical students to improve in this role, given that diagnosis and treatment of patients was not a focus in SUNDdag. However, in interdisciplinary clinical settings, medical students can improve their skills as a medical expert. ${ }^{20,22}$

\section{Volunteerism and suggestions for future changes}

SUNDdag was volunteer-based and organized by students managing a full-time educational schedule. The engagement was reported as being worth their time, however, and was not reported to be a strain on either their life or education. Our students reported that they acquired skills through SUNDdag that they could not have obtained during their education (Table 2). This is in concordance with several other examples of volunteer-based, community-centered, or student-run projects, with educational value beyond the "medical expert" competency for medical students. ${ }^{15,21,35-39}$ SUNDdag contributes to the existing literature by reporting a perceived learning outcome in several of the CanMEDS competencies through a project that was student-founded, 
student-run, volunteer-based, community-centered, and interdisciplinary. To our knowledge, we are the first to report the magnitude of outcomes in such a project.

Volunteerism is characterized by engagement, enthusiasm, and self-sacrifice, but contains uncertainties. In SUNDdag, organizers had no administrative help and no safety net, in contrast with curricular activities, such as clinical interprofessional training with close supervision. ${ }^{7}$ Volunteerism is challenging, but acting responsibly might contain greater learning outcome. ${ }^{35}$

The World Health Organization and several authors have recommended extended interprofessional education and focus on all seven roles in the medical curriculum. . $^{2,8,19,20,32}$ However, it is acknowledged that interprofessional training can be difficult to implement due to lack of time in crowded curricula, lack of interest from teachers and doctors, or lack of administrative support. ${ }^{15,22,34}$ Likewise, our medical students reported a lack of interprofessional training in their education, but regarded it as important for their future jobs.

Eager students lack challenges. As long as the shortage of time and settings exist, medical students must take responsibility for own learning ${ }^{10,22}$ and extracurricular volunteering is one obvious option for self-directed learning, which is known to be an effective approach. ${ }^{35}$ We encourage students to take action and initiate volunteer-based and interdisciplinary projects with self-chosen focus and learning outcomes. We encourage faculties to be socially accountable and support such innovative projects, since the benefits of interprofessional education seem to outweigh the difficulties of implementation. ${ }^{6,30}$ However, it was recently shown that clinical interprofessional training was more expensive than traditional clinical training for students in the health professions. ${ }^{40}$ Therefore, voluntary projects should be promoted. In SUNDdag, the cost-benefit ratio was optimal, with very few expenses due to volunteerism and with extensive student-perceived educational outcomes.

\section{Limitations}

Our study has some limitations. First, students who signed up for SUNDdag may have had pre-existing positive attitudes toward volunteer and interdisciplinary work, which could have influenced their responses in a positive direction. ${ }^{15}$ Second, not all students can find time to volunteer, so it is possible that our results cannot be extrapolated to the entire population. Finally, our study reports perceived improvements in skills, as opposed to objective measurements of enhanced competency. Therefore, further research is warranted to quantify whether activities such as SUNDdag actually result in improved competencies.

\section{Conclusion}

In a university education setting the curriculum for medical students is most focused on the medical expert role and training of the remaining six of the CanMEDS roles is limited. SUNDdag is an example of how an interdisciplinary, volunteer-based, and student-run initiative for medical students could improve learning in the six nonmedical expert CanMEDS competencies and could help medical students gain knowledge of non-health-related professions and tasks. These skills are important for their future careers in a health care system that is increasingly based on interdisciplinary collaboration.

\section{Acknowledgments}

We are grateful to the many volunteers in SUNDdag, from whom we have learned so much. Special thanks are also due to Austin Gagné for careful revision of the manuscript and to André Esbersen for editorial assistance.

\section{Disclosure}

The authors report no conflicts of interest in this work and alone are responsible for the content of this paper. No funding was raised to prepare this manuscript.

\section{References}

1. Goldstein AO, Calleson D, Bearman R, Steiner BD, Frasier PY, Slatt L. Teaching advanced leadership skills in community service (ALSCS) to medical students. Acad Med. 2009;84(6):754-764.

2. Gabel S. Power, leadership and transformation: the doctor's potential for influence. Med Educ. 2012;46(12):1152-1160.

3. Porter ME, Teisberg EO. How physicians can change the future of health care. JAMA. 2007;297(10):1103-1111.

4. Hylin U, Lonka K, Ponzer S. Students' approaches to learning in clinical interprofessional context. Med Teach. 2011;33(4):e204-e210.

5. Lerner S, Magrane D, Friedman E. Teaching teamwork in medical education. Mt Sinai J Med. 2009;76(4):318-329.

6. Hanson S. Teaching health care ethics: why we should teach nursing and medical students together. Nurs Ethics. 2005;12(2):167-176.

7. Jacobsen F, Fink AM, Marcussen V, Larsen K, Hansen TB. Interprofessional undergraduate clinical learning: results from a three year project in a Danish interprofessional training unit. J Interprof Care. 2009;23(1):30-40.

8. McNair RP. The case for educating health care students in professionalism as the core content of interprofessional education. Med Educ. 2005;39(5):456-464.

9. Royal College of Physicians and Surgeons of Canada. The CanMEDS 2005 physician competency framework. Ottawa, Canada: Royal College of Physicians and Surgeons of Canada; 2005. Available from: http:/www.royalcollege.ca/portal/page/portal/rc/common/documents/ canmeds/resources/publications/framework_full_e.pdf. Accessed August 18, 2014. 
10. Danish Health and Medicines Authority. De 7 lægeroller [The seven physician roles]. Copenhagen, Denmark: Danish Health and Medicines Authority; 2013. Available from: http://sundhedsstyrelsen.dk/publ/ Publ2013/05maj/De7laegeroller2udg.pdf. Accessed July 22, 2014.

11. Michaud PA. Reforms of the pre-graduate curriculum for medical students: the Bologna process and beyond. Swiss Med Wkly. 2012;142: w13738.

12. Stafford S, Sedlak T, Fok MC, Wong RY. Evaluation of resident attitudes and self-reported competencies in health advocacy. BMC Med Educ. 2010;10:82.

13. Rademakers JJ, de Rooy N, Ten Cate OT. Senior medical students' appraisal of CanMEDS competencies. Med Educ. 2007;41(10): 990-994.

14. Abbas MR, Quince TA, Wood DF, Benson JA. Attitudes of medical students to medical leadership and management: a systematic review to inform curriculum development. BMC Med Educ. 2011;11:93.

15. O’Carroll V, Braid M, Ker J, Jackson C. How can student experience enhance the development of a model of interprofessional clinical skills education in the practice placement setting? J Interprof Care. 2012;26(6):508-510.

16. Borleffs JC, ten Cate TJ. Competency-based training for internal medicine. Neth J Med. 2004;62(10):344-346.

17. Dharamsi S, Ho A, Spadafora SM, Woollard R. The physician as health advocate: Translating the quest for social responsibility into medical education and practice. Acad Med. 2011;86(9):1108-1113.

18. Woollard B, Boelen C. Seeking impact of medical schools on health: meeting the challenges of social accountability. Med Educ. 2012;46(1):21-27.

19. Reid AM. Developing innovative leaders through undergraduate medical education. Educ Prim Care. 2013;24(1):61-64.

20. Norgaard B, Draborg E, Vestergaard E, Odgaard E, Jensen DC, Sorensen J. Interprofessional clinical training improves self-efficacy of health care students. Med Teach. 2013;35(6):e1235-e1242.

21. Seif G, Coker-Bolt P, Kraft S, Gonsalves W, Simpson K, Johnson E. The development of clinical reasoning and interprofessional behaviors: service-learning at a student-run free clinic. J Interprof Care. 2014; 28(6):559-564.

22. Ericson A, Masiello I, Bolinder G. Interprofessional clinical training for undergraduate students in an emergency department setting. J Interprof Care. 2012;26(4):319-325.

23. Orlando R 3rd, Haytaian M. Physician leadership: a health-care system's investment in the future of quality care. Conn Med. 2012;76(7): 417-420.

24. Sakai DH, Marshall S, Kasuya RT, et al. Medical school hotline: interprofessional education: future nurses and physicians learning together. Hawaii J Med Public Health. 2012;71(6):168-171.

25. MacDonnell CP, Rege SV, Misto K, Dollase R, George P. An introductory interprofessional exercise for healthcare students. Am J Pharm Educ. 2012;76(8):154.
26. Harward DH, Tresolini CP, Davis WA. Can participation in a health affairs interdisciplinary case conference improve medical students' knowledge and attitudes? Acad Med. 2006;81(3):257-261.

27. Cox M, Pacala JT, Vercellotti GM, Shea JA. Health care economics, financing, organization, and delivery. Fam Med. 2004;36 Suppl: S20-S30.

28. Kraushaar LE, Kramer A. Are we losing the battle against cardiometabolic disease? the case for a paradigm shift in primary prevention. $B M C$ Public Health. 2009;9:64.

29. Capewell S, O’Flaherty M. Can dietary changes rapidly decrease cardiovascular mortality rates? Eur Heart J. 2011;32(10):1187-1189.

30. Boelen C, Dharamsi S, Gibbs T. The social accountability of medical schools and its indicators. Educ Health (Abingdon). 2012;25(3): 180-194.

31. Klevens J, Valderrama C, Restrepo O, Vargas P, Casasbuenas M, Avella MM. Teaching community oriented primary care in a traditional medical school: a two year progress report. J Community Health. 1992;17(4):231-245.

32. World Health Organization. Framework for action on interprofessional education and collaborative practice. Geneva, Switzerland: World Health Organization; 2010. Available from: http://whqlibdoc.who.int/hq/2010/ WHO_HRH_HPN_10.3_eng.pdf. Accessed September 3, 2014.

33. O'Connell MT, Pascoe JM. Undergraduate medical education for the 21st century: leadership and teamwork. Fam Med. 2004;36 Suppl: S51-S56.

34. Rice K, Zwarenstein M, Conn LG, Kenaszchuk C, Russell A, Reeves S. An intervention to improve interprofessional collaboration and communications: a comparative qualitative study. $J$ Interprof Care. 2010;24(4):350-361.

35. Meah YS, Smith EL, Thomas DC. Student-run health clinic: novel arena to educate medical students on systems-based practice. Mt Sinai J Med. 2009;76(4):344-356.

36. Wee LE, Yeo WX, Tay CM, Lee JJ, Koh GC. The pedagogical value of a student-run community-based experiential learning project: The Yong Loo Lin School of Medicine Public Health Screening. Ann Acad Med Singapore. 2010;39(9):686-686.

37. Smego RA Jr, Costante J. An academic health center-community partnership: the Morgantown Health Right Free Clinic. Acad Med. 1996;71(6):613-621.

38. Deonandan R, Patel P, Winterbottom R. A student-run peer-reviewed journal: an educational tool for students in the health sciences. Adv Med Educ Pract. 2012;3:1-5.

39. Cooksey NR. Bridging the gap between textbook and maternity patient: a nurse-developed teaching model for first-year medical students. Birth 2010;37(4):325-333.

40. Haines TP, Kent F, Keating JL. Interprofessional student clinics: an economic evaluation of collaborative clinical placement education. J Interprof Care. 2014;28(4):292-298.
Advances in Medical Education and Practice

\section{Publish your work in this journal}

Advances in Medical Education and Practice is an international, peerreviewed, open access journal that aims to present and publish research on Medical Education covering medical, dental, nursing and allied health care professional education. The journal covers undergraduate education, postgraduate training and continuing medical education

\section{Dovepress}

including emerging trends and innovative models linking education, research, and health care services. The manuscript management system is completely online and includes a very quick and fair peer-review system. Visit http://www.dovepress.com/testimonials.php to read real quotes from published authors. 